First Break Article

\title{
A Geophysical Journey around Ireland
}

James. A. Hodgson, Minerex Geophysics Ltd.

Shane Donahue, University College Dublin, Yvonne O'Connell, Apex GeoServices Ltd., Hartmut Krahn, Minerex Geophysics Ltd, Graham Reid BRG LTD and Mike Young Geological Survey of Northern Ireland.

'In Ireland the inevitable never happens and the unexpected constantly occurs'. Sir John Pentland Mahaffy.

Before this year's Near Surface Conference in Dublin, I would like to invite you on a gentle stroll through the geological and geophysical highways and byways of Ireland. Along the way we will look at the different aspects of near surface geophysics that are currently used in Ireland as well as sampling what Ireland has to offer.

This geophysical journey stretches from geotechnical investigations in the hustle and diversity of Dublin to gravel quarries in the mountains of Wicklow, to long flat and wet peat bogs in the midlands, investigating karst features in Cork to mineral exploration in county Limerick and an aerial tour of the north.

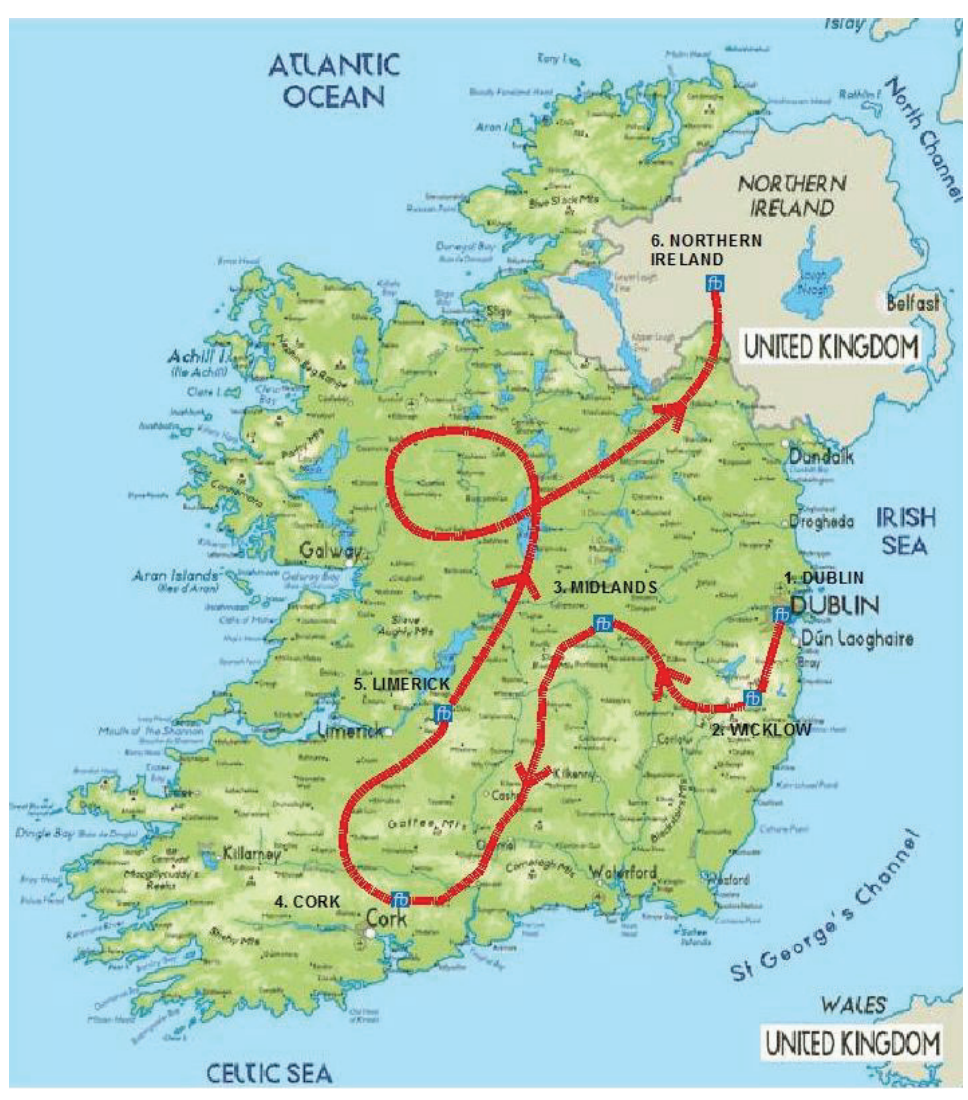

Figure 1: First Break Tour around Ireland. (1) Dublin, (2) Wicklow, (3) Irish Midlands, (4) Cork, (5) Limerick \& (6) Northern Ireland. 


\section{Geotechnical Needs in Dublin}

Ireland's capital city Dublin is a vibrant modern cosmopolitan city which has seen many phases of development from Viking settlement in $988 \mathrm{AD}$ to the modern $21^{\text {st }}$ century property boom (now shuddering to a halt) in the last few years. This recent development has resulted in a need for greater understanding of site conditions and geotechnical properties as larger developments get concentrated into smaller areas.

Much of the city of Dublin is underlain by a glacial deposit known colloquially as Dublin boulder clay (DBC). This glacial till was deposited beneath the ice sheet that covered much of Ireland during the Pleistocene period, some 18,000 years ago. It is known that the ice thickness in Dublin was approximately $1 \mathrm{~km}$ and that several advances and retreats of the glaciers occurred in the area. The grinding action of this sheet as it eroded the underlying rocks coupled with its loading effect resulted in the formation of a hard lodgement till which in engineering terms is characterised by being hard, of very high stiffness and of low permeability. A particular characteristic of the Irish tills, say when compared to similar material in the UK, is the presence of large cobbles and boulders.

A number of large infrastructural projects in Dublin over recent years, such as the Dublin Port Tunnel, Metro North and Rail Interconnector have made use of geophysical techniques for investigating ground conditions and providing geotechnical design parameters. However, due to the large amount of noise, on most if not all urban sites in Dublin city centre, the choice of geophysical technique is severely limited. Over recent years, however, both geophysicists and geotechnical engineers have observed the benefits of using surface wave techniques such as the Multichannel Analysis of Surface Waves (MASW) in urban environments. The large amplitude, low frequency nature of surface waves relative to body waves makes them far more suitable for investigations in urban areas, such as Dublin, where first arrivals may be impossible to detect. An advantage of the MASW approach over other similar surface wave methods, such as the Spectral Analysis of Surface Waves (SASW) is the ability of the technique to identify and separate fundamental and higher mode surface waves.

An example of the 2D shear wave velocity $\left(V_{s}\right)$ distribution of a Dublin city centre site, located south of the River Liffey is shown in Figure 2, along with a summary of the various stages required to produce such a plot, from multichannel data acquisition, to dispersion curve picking and inversion. This MASW data was acquired with a roll-along approach using a land streamer consisting of 24 plate coupled $4.5 \mathrm{~Hz}$ geophones. The source used to 
generate the seismic data was a tractor mounted weight drop (Fig. 3) and shots were acquired at $6 \mathrm{~m}$ intervals. As shown in Figure 2c, there is quite a large variation in the subsurface distribution of $V_{s}$ at this site, with velocities of $200-700 \mathrm{~m} / \mathrm{s}$ measured for the glacial till material $\left(0-10 \mathrm{~m}\right.$ approx. Below this depth the very high velocity material $\left(\mathrm{V}_{\mathrm{s}}>\right.$ $900 \mathrm{~m} / \mathrm{s}$ ) has been verified using borehole data as limestone bedrock, the depth to which appears to be quite variable at this site.

(a)
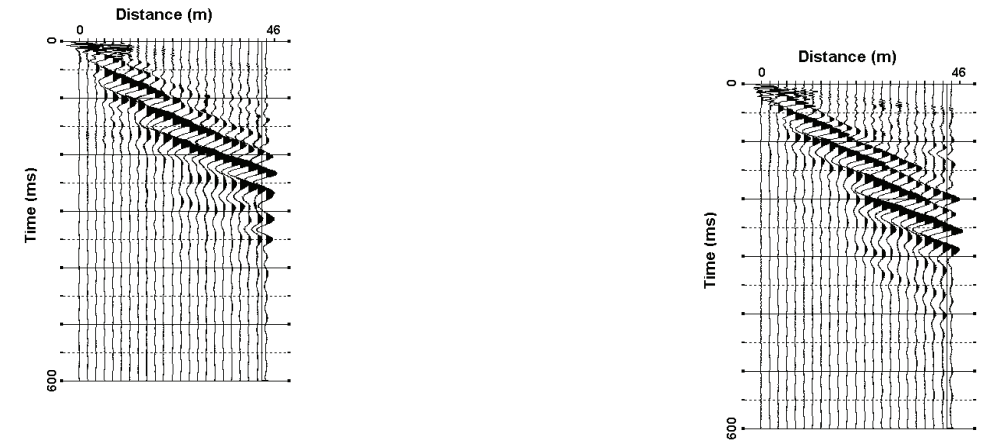

(b)
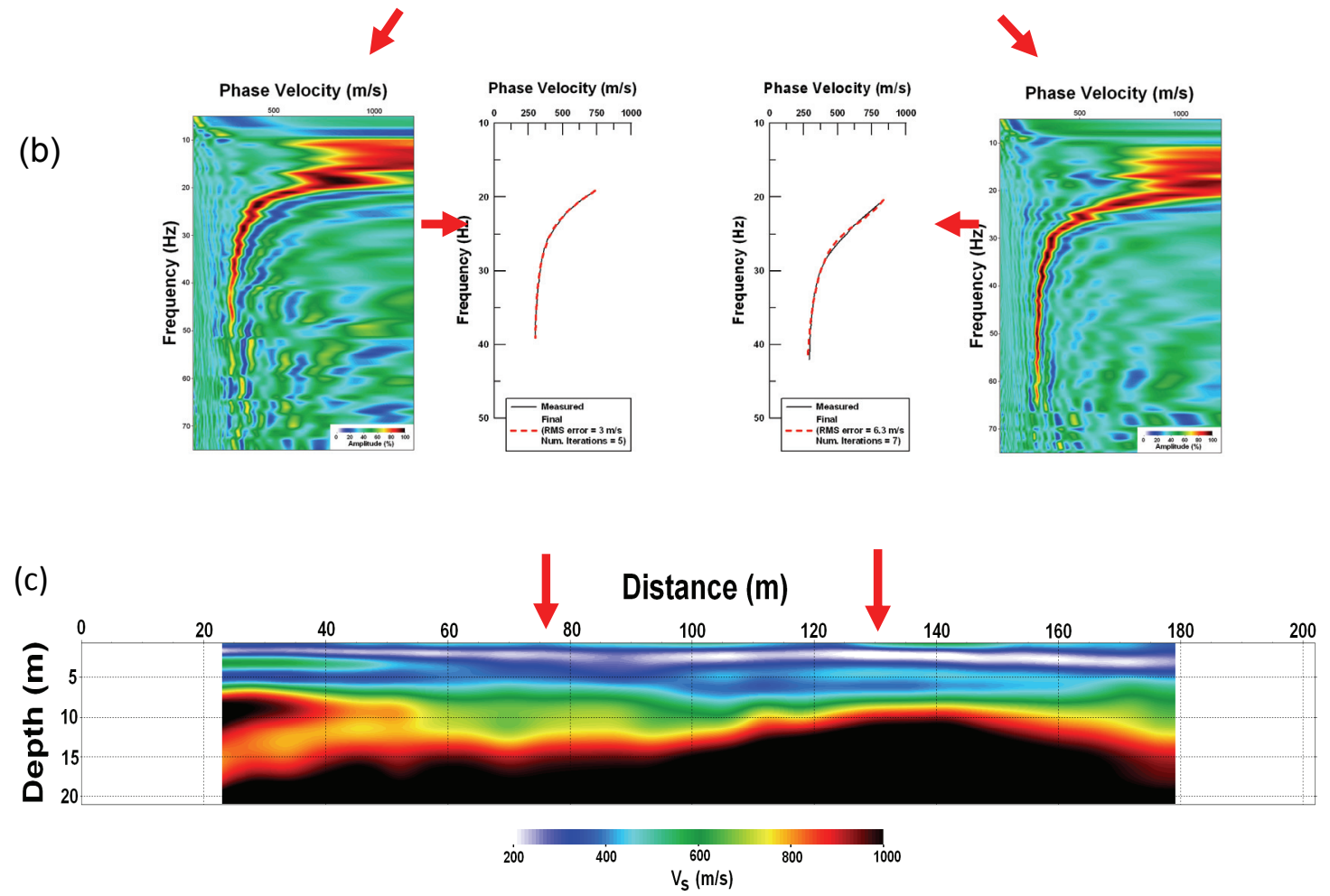

Figure 2: 2D MASW $V_{s}$ Figure 2: Profile from a Dublin city centre site, south of the River Liffey: (a) multichannel seismic data, (b) dispersion curve image and inversion and (c) $2 \mathrm{D} \mathrm{V}_{\mathrm{s}}$ image combining inverted $1 \mathrm{D} \mathrm{V}_{\mathrm{s}}$ profiles. 


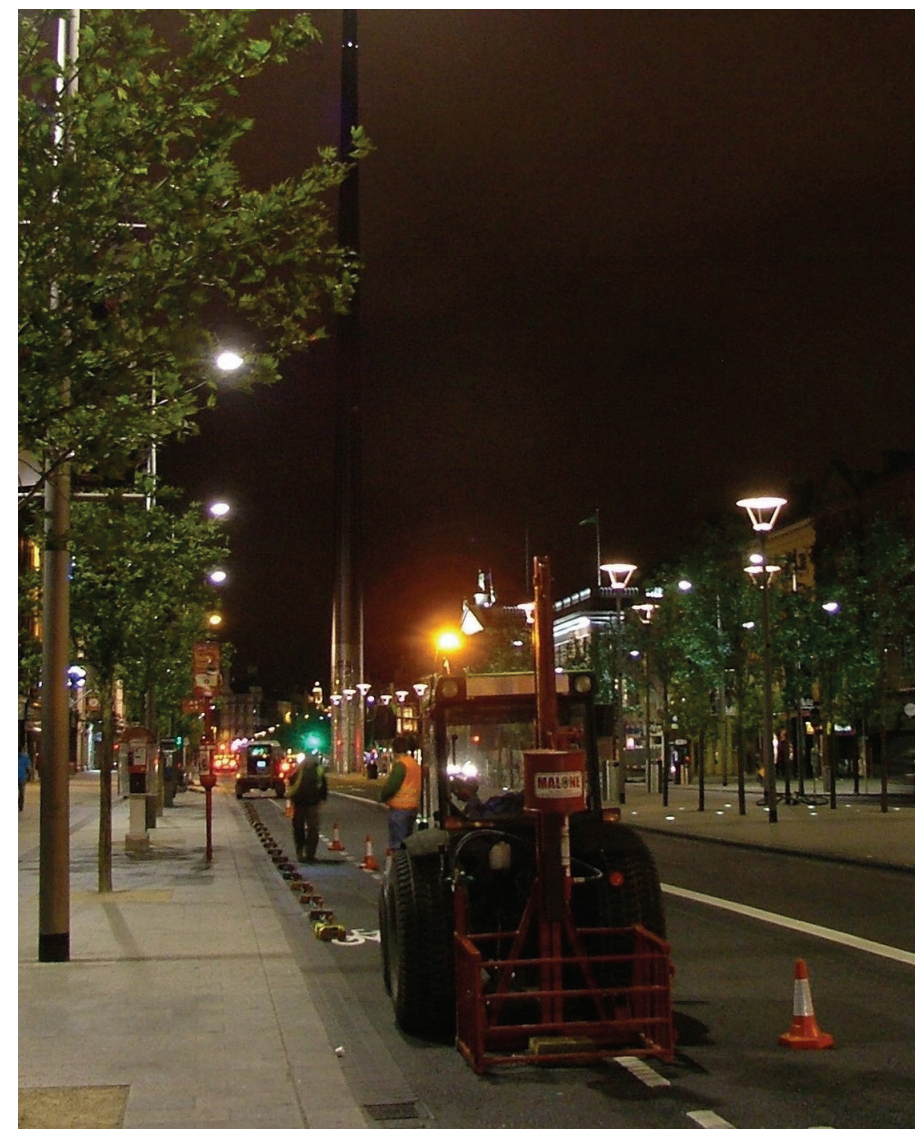

Figure 3: Acquisition of 2D roll-along MASW data in Dublin city centre.

\section{Sand \& Gravel and Granite Quarries, Co. Wicklow}

We now journey south from Dublin to the rolling granite mountains and glacial deposits in County Wicklow. Wicklow is often referred to as the garden of Ireland and contains many beautiful views of hills and lakes. The landscape has been the backdrop to many films including Braveheart and Excaliber. The landscape also hosts sand and gravel deposits and geophysics is routinely used to help map the extent and thickness of these deposits. 


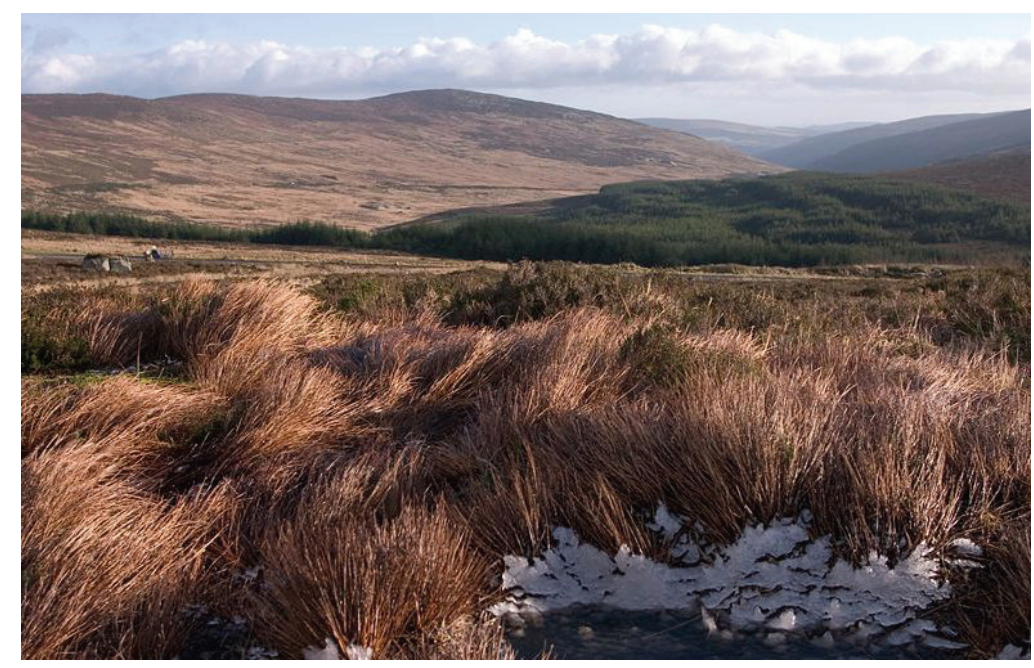

Figure 4: The Wicklow Mountains

In a recent site investigation survey by Minerex Geophysics Ltd, an evaluation of sand and gravel resources were made for the potential development of a sand and gravel quarry. in County Wicklow. An EM31 ground conductivity survey was carried out over an area of bog and agricultural land to provide an initial assessment of an area for Due to the large size of the site (190 acres) and difficult terrain the EM31 is an ideal tool for providing a quick reconnaissance of the area. Figure 5 highlights the low conductivity areas in blue indicating shallow deposits of sand and gravel. Follow up surveys including detailed 2D resistivity and seismic refraction profiling (Figure 6) based on the initial EM31 survey allowed interpretations of the thickness of the deposits and hence a calculation of the available potential tonnage across the site. 


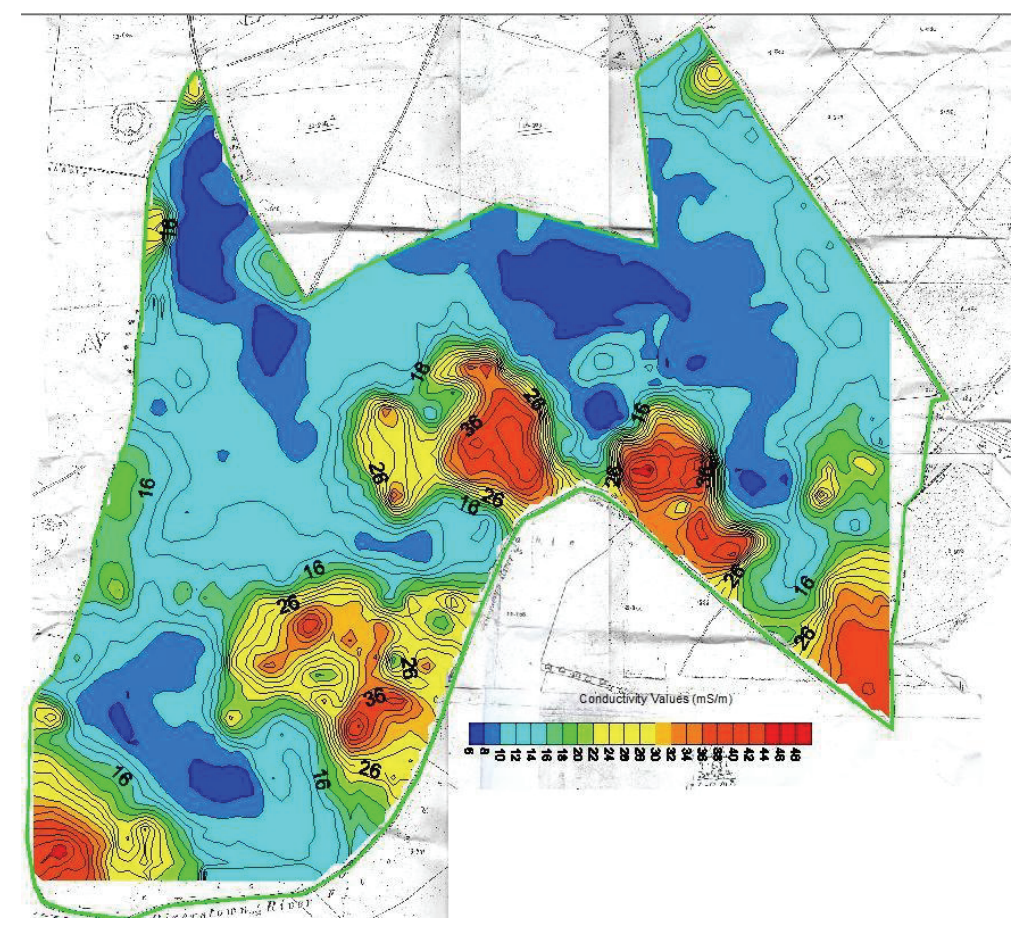

Figure 5: A conductivity contour map highlighting areas of gravel (in blue).

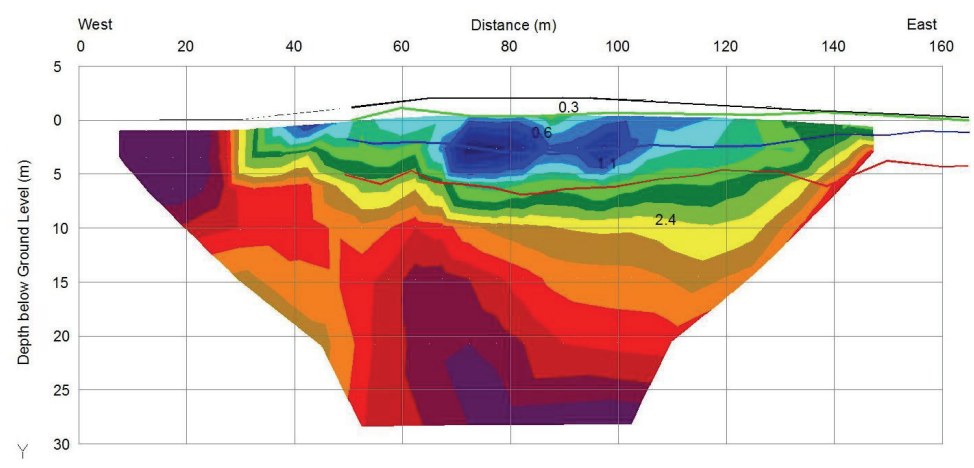

Figure 6: 2D-Resistivity \& Seismic cross-section over gravel lens. 


\section{Peat Thickness Mapping - The Irish Midlands}

Travelling inland from the mountains of Wicklow we arrive at flat wet peatlands of the Irish Midlands. Peat or 'turf' has played an important role in Ireland over the centuries. The turf was cut from the bog and dried and used as fuel in most houses. There are two main types of peat bog that account for approximately $14 \%$ of Irelands' land area; blanket bogs which are generally found in the western half of the country and mountainous areas; and raised bogs which are mainly in the midlands and typically have peat thicknesses between $4 \mathrm{~m}$ and $10 \mathrm{~m}$. Milled peat has been commercially extracted by Bord $\mathrm{Na}$ Mona from the raised bogs for energy generation since 1946. In 2008 a LIDAR survey of the Bord Na Mona bog infrastructure (covering $69,000 \mathrm{Ha}$ ) was commissioned as part of their peat resource assessment project. To complete this assessment GPR surveys to map peat thickness are currently being carried out by APEX Geoservices Limited across $35,000 \mathrm{Ha}$ of production bogs.

The GPR survey is being carried out using a $100 \mathrm{MHz}$ shielded antenna towed behind a quad bike with profiles collected every $4^{\text {th }}$ field $(60 \mathrm{~m})$. The GPR system is triggered by a hub mounted electronic encoder calibrated to sample at $200 \mathrm{~mm}$ intervals and linked to RTK GPS to provide accurate positional information written directly to the trace headers. The positional accuracy of the RTK GPS data is $\pm 20 \mathrm{~mm}$ in both lateral position and height. The GPR monitor is mounted on the front of the quad to enable onsite QC of the data and to effectively target the placement of physical soundings. The soundings are carried out using a peat auger, sometimes known as a "Russian Sampler" where the sampler is pushed into the peat and then rotated to trap the sample in the chamber. The position of each probe is recorded as a digital mark on each profile to enable accurate relocation of the calibration data. See Figure 7 below for survey configuration. 


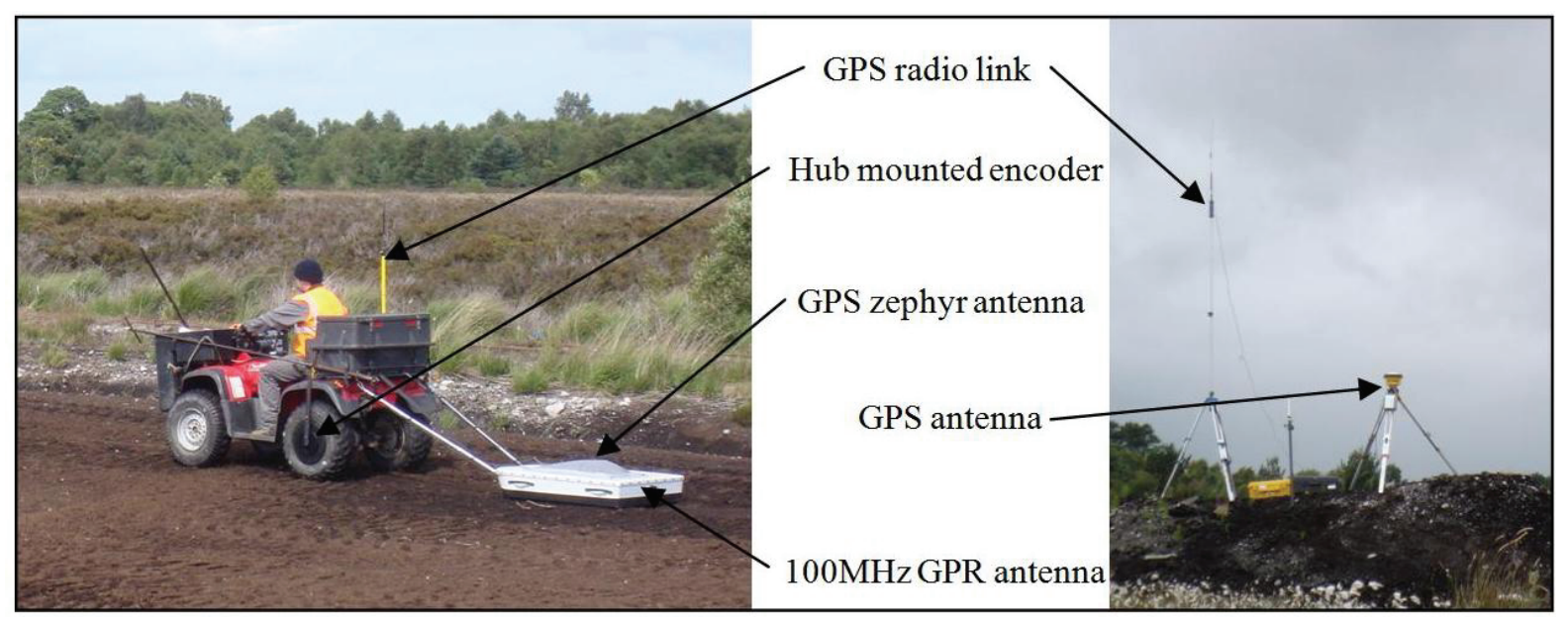

Figure 7: a) GPR survey configuration and b) GPS base station

Figure 8 below shows an example processed GPR profile before and after the topographic correction. The ability to view topographically corrected data gives a much greater appreciation of the geomorphology of a site resulting in a more confident interpretation of the data.

Figure 8: Example GPR data: a) processed section b) topographically corrected
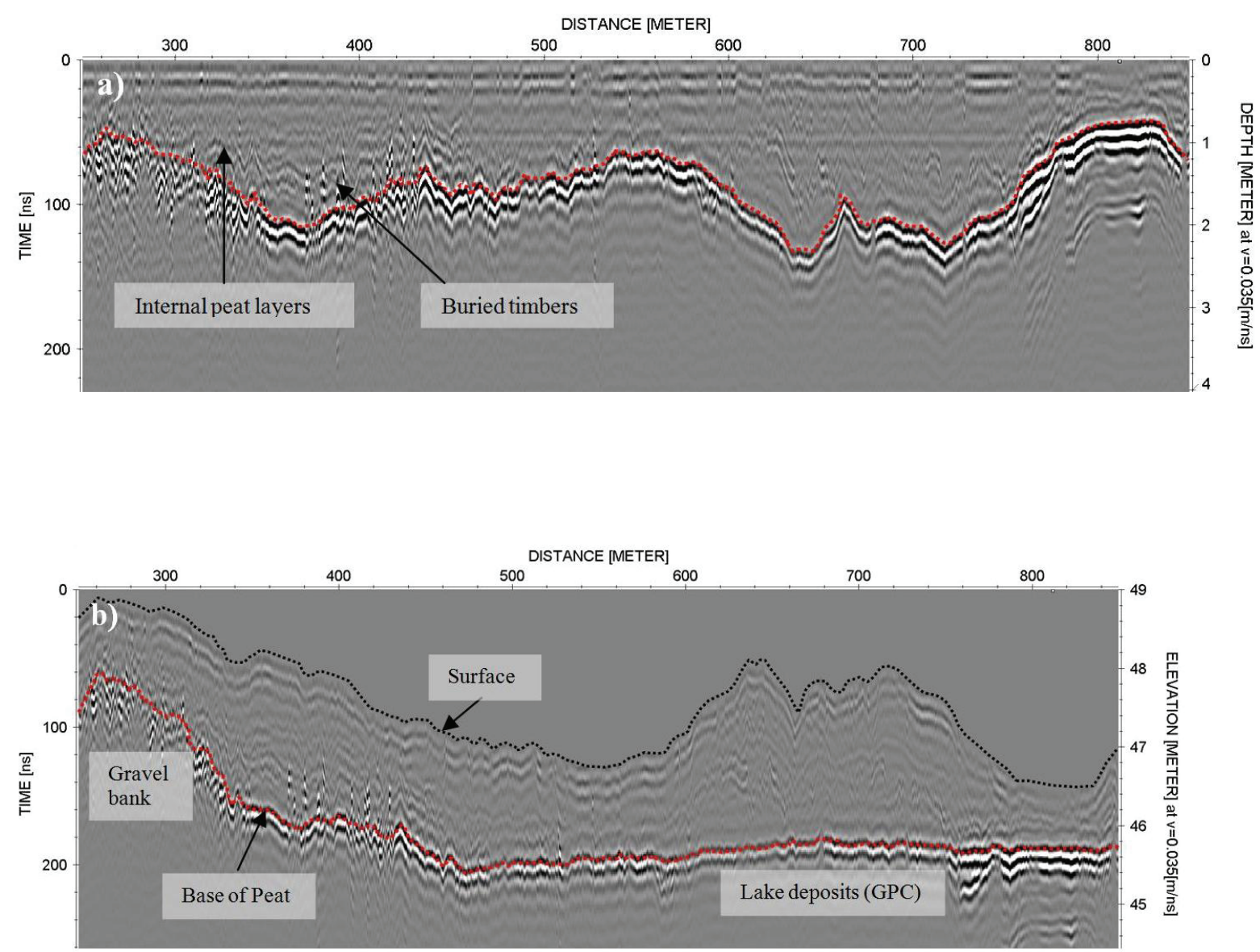
Although this work is being carried out as a commercial venture with the overriding objective to determine the peat thickness, it has become apparent that a great deal of information on the sub-peat soils can be determined from the GPR data. It is possible to determine the type of sub-peat deposit and depositional history of an area from the assessment of the GPR response. Different reflection characteristics from within the peat layers can also provide information on the origin and composition of the peat layers.

The peat thickness is used to make accurate volume estimates of the peat resource and to draw up production plans (see Figure 9).

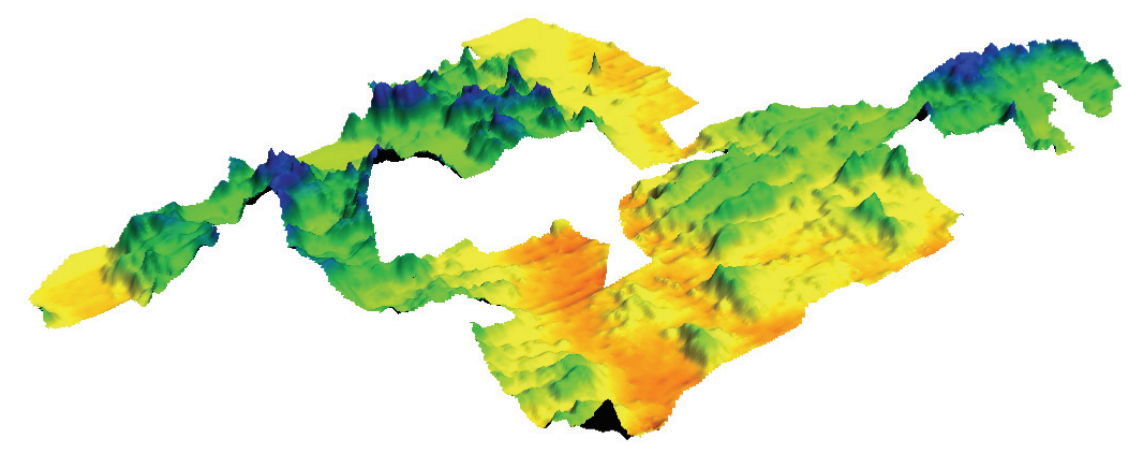

Figure 9: 3D plot of elevation of base of peat showing sub-peat topography.

The use of GPR for the assessment of peat thickness is highly effective and provides a level of accuracy that would not be practically realised using other means. The data is proving to be invaluable in the future planning of the remaining peat resources of the Irish Midlands.

\section{Karst Investigations Co. Cork}

Heading south through the counties of Kilkenny and Tipperary we arrive in beautiful Cork. In an area famous for the Blarney stone it is karstic limestones that are of most interest to the geophysicist. Limestone pavement and cavities can create numerous problems for engineers (Fig. 10). 


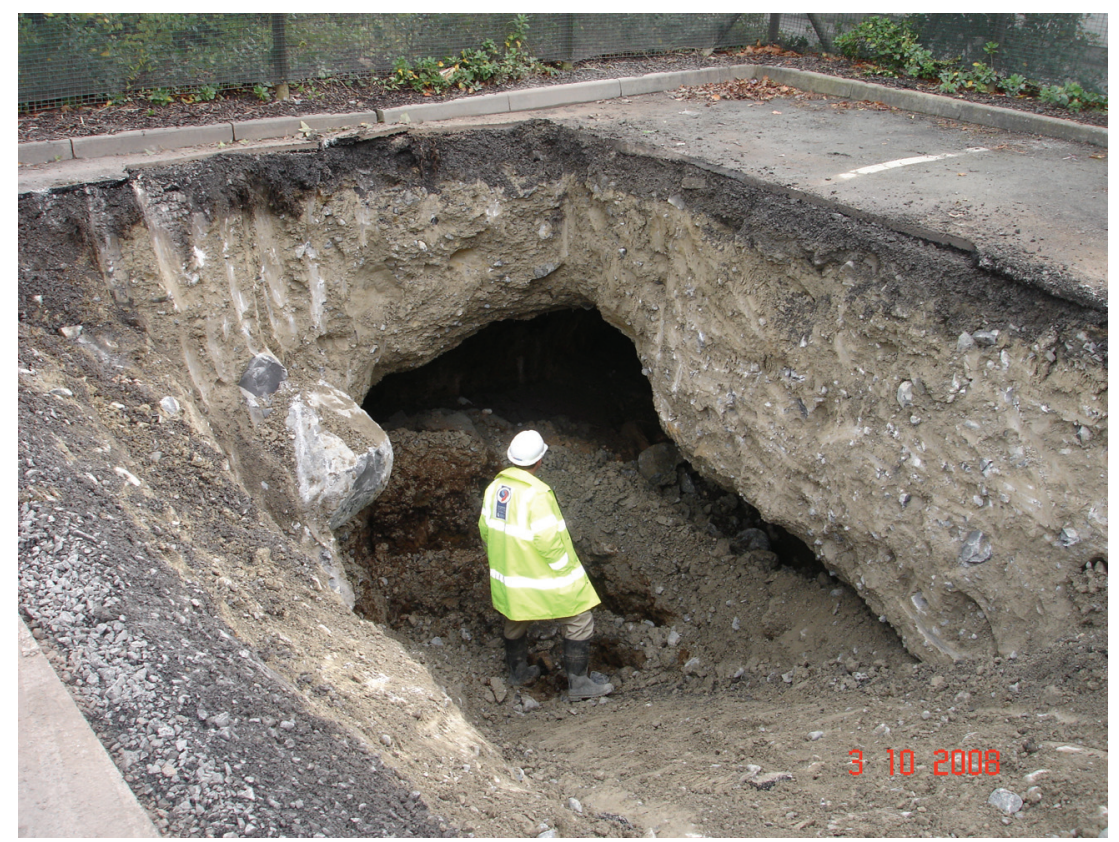

Figure 10: Inspection of a cave.

A number of road schemes across Ireland have used Microgravity and 2D-Resistivity surveys to understand ground conditions particularly in areas where the bedrock geology consists of pure limestones that have the potential to be karstified. During a proposed road scheme close to the city of Cork a relatively large $10 \times 10 \mathrm{~m}$ grid of microgravity was carried out by Minerex Geophysics Ltd. A total of approx. 1200 stations were surveyed. 2DResistivity profiles were acquired along or close to the centreline of the proposed road alignment. The gravity contour map indicates values in MicroGal that were reduced to a local reference station after corrections were computed. The 2D-Resistivity is shown below the gravity and the blue line on the contour map indicates the locations of the resistivity data. A significant gravity low exists in the data with values dropping from 263 to 123 MicroGal over a short distance. No visible surface features correspond with this gravity low. The gravity anomaly as seen in plan view is mirrored by the low resistivity values seen on the crosssection. Low resistivities represent a karstified rock or overburden. High resistivities indicate compact limestone. The gravity data indicates the location of the anomaly as it trends at an angle across the proposed road alignment. The resistivity data shows the vertical and lateral extend of the anomalous rock area. 


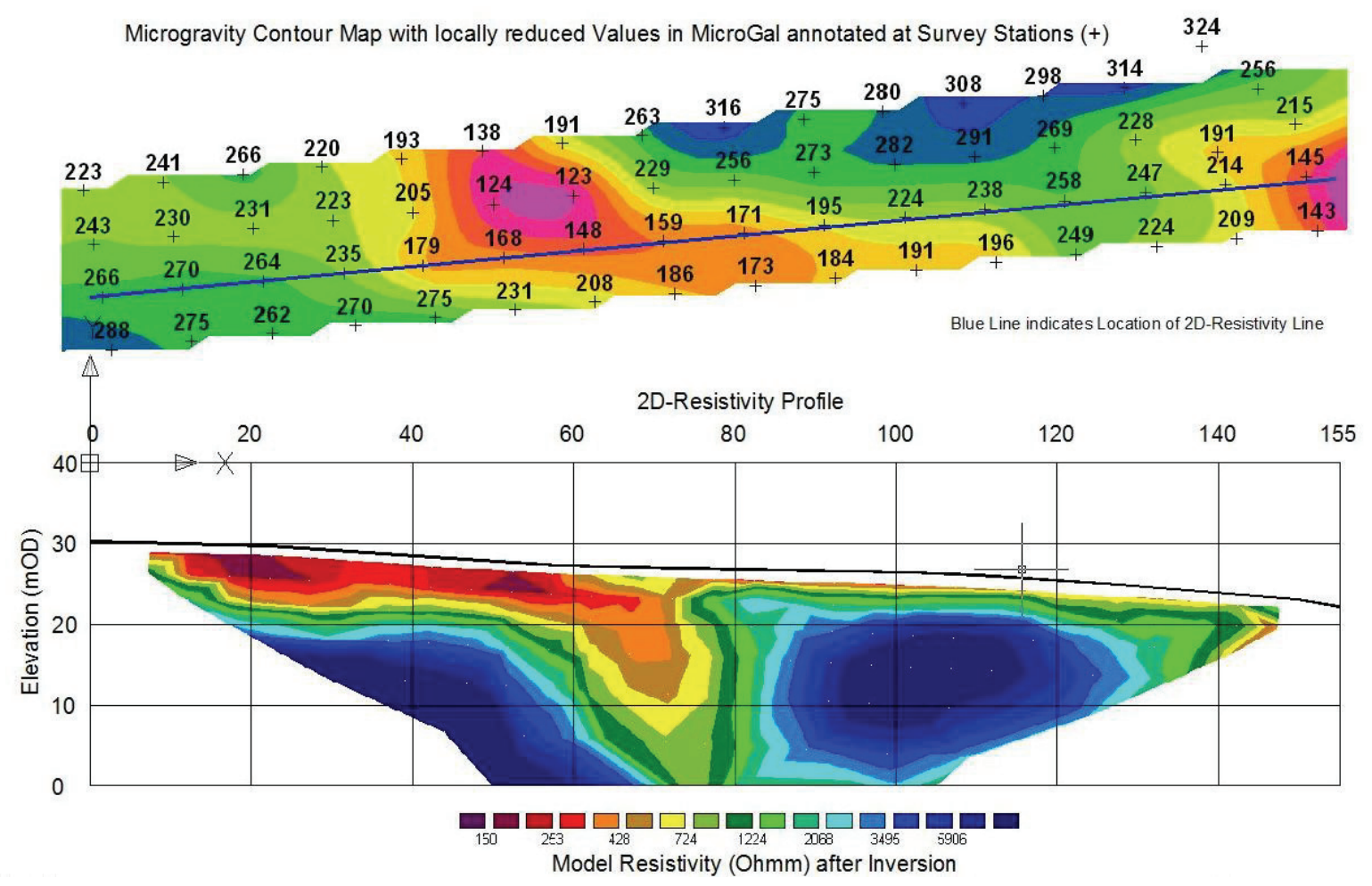

Figure 11: Microgravity and 2D resistivity profiles across karstified zone.

\section{IP \& Resistivity Surveys Pallas Green, Co. Limerick}

A short journey northwards brings us to counties Limerick and Clare where mining exploration is on-going. Mining has occurred throughout Ireland for thousands of years. Excellent examples of prehistoric gold jewellery from local sources are found in the National Museum in Dublin. However, following the discovery of the Tynagh Mine (Co. Galway) in 1960, Ireland has changed from small-scale productions to being recognised as a worldclass zinc \& lead ore field. Tara Mine in County Meath is the largest Lead-Zinc mine in western Europe and a field trip will visit the mine as part of the Near Surface conference. Extensive exploration has been carried out across the prospective central Midlands and western regions, where a multidisciplinary approach including geological, geochemical and geophysical techniques has been employed.

The Pallas Green area was identified as being highly prospective because of favourable geology, structure, alteration, mineral occurrences that were seen to be coincident with regional scale basement trends and on a local scale strong soil geochemical anomalies were found. Diamond drilling initially targeted regions with favourable geology and anomalous geochemical signatures in the soil. 
Geophysical techniques were employed by BRG Ltd., to help target drilling once mineralisation had been intersected and to aid the ongoing geological and structural interpretations. Mineralisation in this region is normally found at the base of a highly resistive sequence of mudbank limestones, which overlie a more argillaceous limestone sequence with a low resistivity signature. In the example presented in Figures $12 \& 13$, regional scale drilling with holes approximately $1 \mathrm{~km}$ apart had intersected significant alteration and lowgrade mineralisation. Lithogeochemical analysis on the core confirmed the anomalous nature of the intersections and defined a target further to the south (down dip). The first stepout hole (A), 500m to the south, intersected massive sulphides at a depth of c.150m (Over $3 m$ at $>20 \% \mathrm{Zn} \mathrm{\&} \mathrm{4 \%} \mathrm{Pb).} \mathrm{IP} \mathrm{\&} \mathrm{Resistivity} \mathrm{surveys} \mathrm{were} \mathrm{carried} \mathrm{out} \mathrm{across} \mathrm{this} \mathrm{zone} \mathrm{with}$ the aim of more accurately targeting the mineralised zones and assisting with the geological and structural interpretations.

A Gradient Array Induced Polarisation survey was used to map the apparent resistivity and chargeability responses for this region and assisting with the refinement of the structural and geological model for this area, which has generally poor outcrop. The images below show the Apparent Resistivity (Fig.12) and Chargeability (Fig.13) centred on the discovery drillhole (hole A). The strong NW-SE grain evident on the Apparent Resistivity image is coincident with a thinning of the mudbank sequence and subsequent shallowing of the argillaceous limestones giving the pronounced low resistivity lineament. This feature may also be coincident with small scale faulting that is controlling the long axis of the massive sulphide lens. The Chargeability image shows a number of distinct anomalies, again with a northwestsoutheast orientation. The anomaly centred on drillhole $B$ is caused by the massive sulphides, which attain a maximum thickness of $12 \mathrm{~m}$ in this hole. The equally strong anomaly to the southwest is not related to mineralisation but is interpreted as a water bearing fault / fracture zone that is coincident with the margin of a resistivity high.

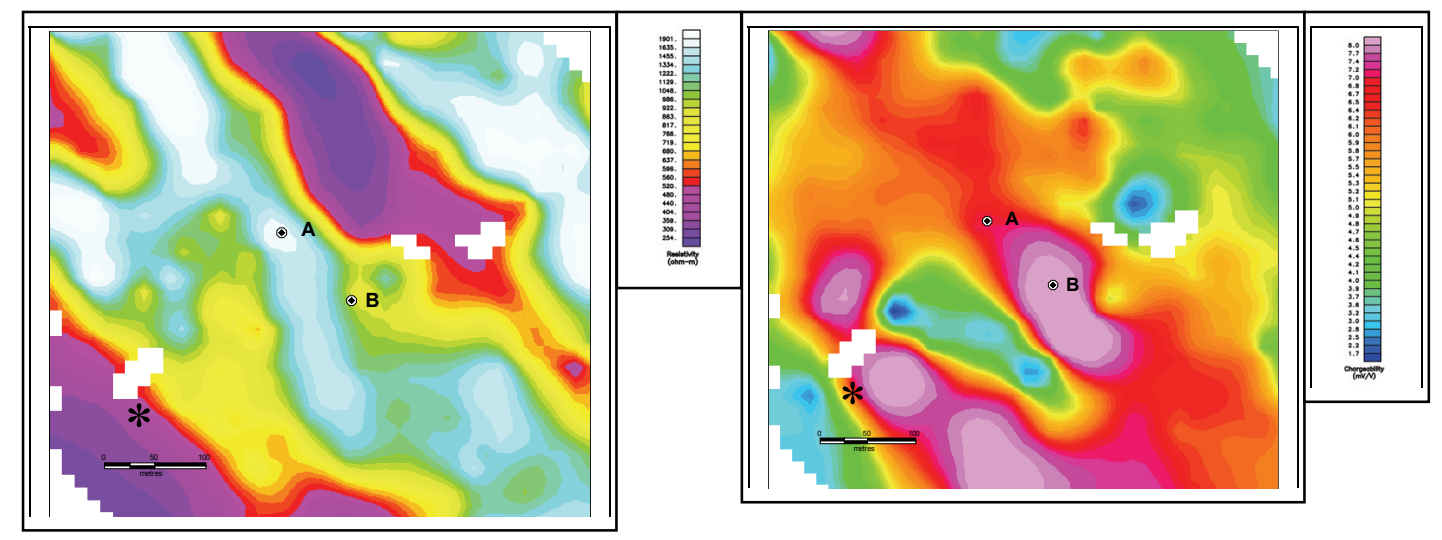


Drillhole B was also proximal to a Mise-a-la-messe (MALM) anomaly acquired from a current electrode placed in the mineralisation in drillhole $A$, with a surface potential grid around the source. This drillhole was completed after relatively unsuccessful drillholes were completed on $100 \mathrm{~m}$ centres to west, north, east and south of drillhole A. Drillhole B intersected over $12 \mathrm{~m}$ of massive sulphides, dominated by pyrite/marcasite and including over $8 \mathrm{~m}$ at $3.9 \% \mathrm{Zn}$. The relative success of the method at this location is undoubtedly helped by the continuity of the sulphides between the two drillholes. MALM surveys were carried out using other drillholes in the area and these proved to be ambiguous, probably reflecting the discontinuous nature of the massive sulphides distal to the core zone.

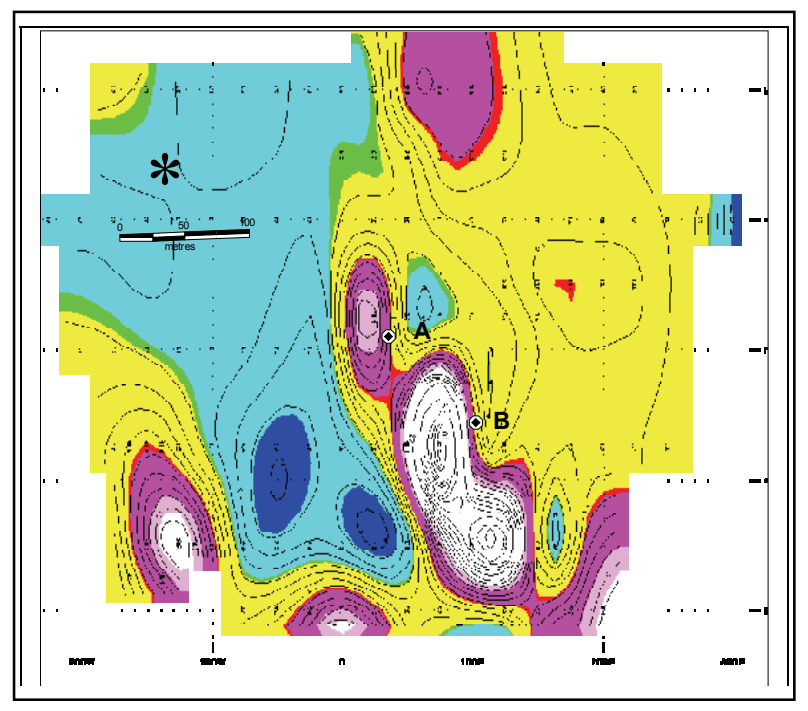

Figure 14: Chargeabilities from MALM Drillhole A (magenta to white as high zones)

\section{Airborne geophysical survey of Northern Ireland}

We now jump in a plane and head across the border to Northern Ireland where The Geological Survey of Northern Ireland (GSNI) has completed important regional and detailed geophysical surveys in recent years.

In 2005-6 GSNI commissioned a national low-level airborne geophysical survey of Northern Ireland, as part of the Tellus Project. The survey was flown for GSNI by the Joint Airbornegeoscience Capability, a partnership of the BGS and the Geological Survey of Finland (GTK), with a De Havilland Twin Otter aircraft, used previously for geophysical surveys in 
Finland. Magnetic gradiometer, 256 channel radiometrics and four frequency EM data were acquired, at $200 \mathrm{~m}$ line spacing and $56 \mathrm{~m}$ ground clearance. The objectives of the work were to generate environmental baseline data and to promote investment in natural resources exploration.

The magnetic anomaly imagery (Fig. 15) reveals structural detail within the magnetized domains of Northern Ireland, notably the Palaeocene Antrim Lavas, prominent intrusions in the south-east and the Palaeozoic Tyrone Igneous Complex. Several generations of Tertiary dolerite dykes are recognized and well delineated. Nickel and platinum soil geochemistry anomalies correspond with some magnetic anomalies.

The electrical conductivity imagery distinguishes between major formations and reveals previously unmapped regional and local structures, some of which, in the west, correlate with soil and stream gold anomalies. The method has also detected anthropogenic effects such as pollution plumes down-gradient of landfills. The detailed gamma-ray spectrometry imagery shows significant detail and reflects variations in bedrock and soil type. Radiometric data are being used in radon-risk, soil-carbon and caesium fallout-studies.

The Tellus Project, which also included national soil and stream geochemical sampling studies, was recognized by two industry awards in 2008: the Mining Journal Outstanding Achievement Award ('Country' category), and the Innovation and Best Practice (Central Government category) from the Association for Geographic Information'. Release of the results prompted a surge in mineral prospecting, with $70 \%$ of Northern Ireland licensed for exploration.

Currently, a second phase of Tellus investment is focused on natural resources exploration. In the geothermal sector, GSNI has commissioned MT and gravity surveys in the Lough Neagh Basin and the Mourne Mountains, to augment previous drilling and seismic surveys and follow up high geothermal gradients observed in deep wells. GSNI is also promoting the possibility of using Permian salt beds for underground gas storage and three companies have licensed areas for investigation; gravity and electrical resistivity tomography have contributed to these assessments. 


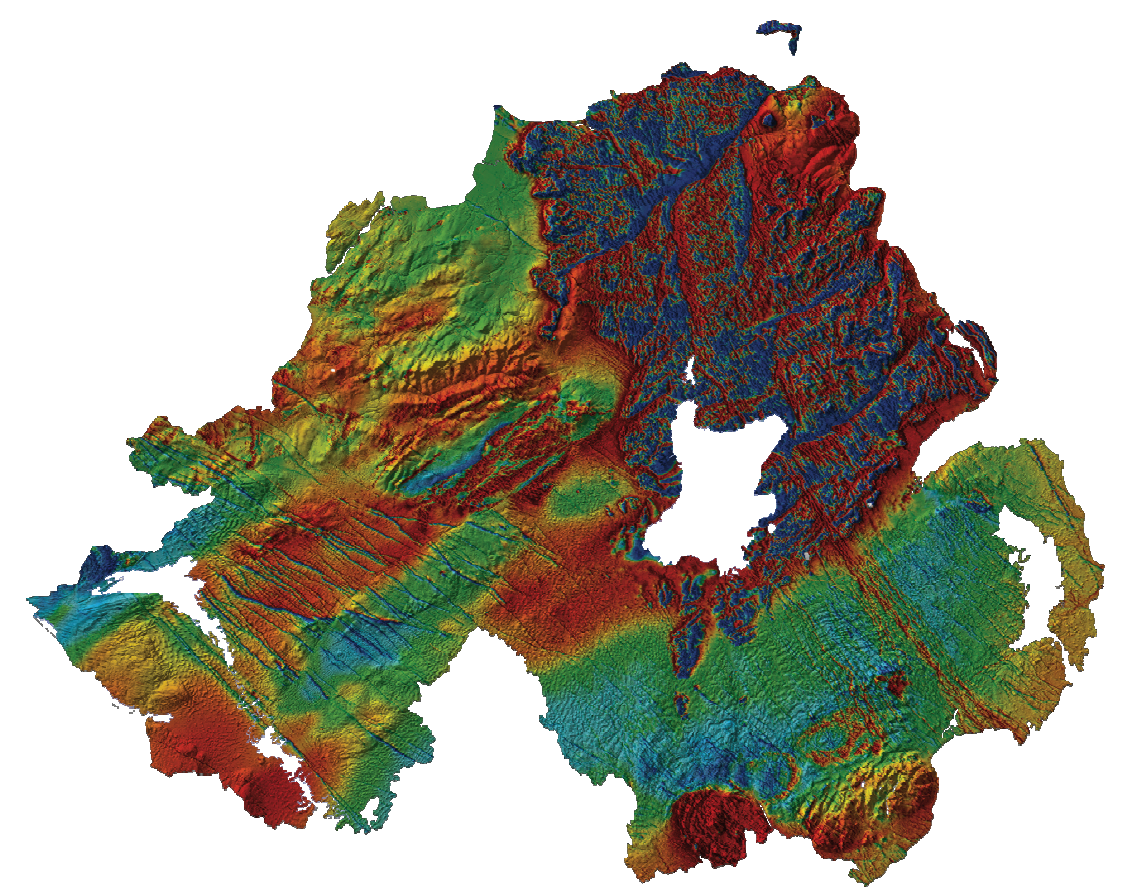

Figure 15: Northern Ireland: total magnetic intensity, superimposed on a digital terrain model (DTM). (Red: high magnetization, blue: low magnetization).

\section{Join us in September}

As we have seen on our journey through Ireland, extensive near surface geophysics has, and continues to be carried out in all areas for numerous different projects. One of the great benefits of geophysics is the chance it gives you to visit and experience new and interesting places. So on your journey to NEAR Surface 2009 in Dublin this September, why don't you explore a little more or what Ireland has to offer both as a visiting geophysicist and as an interested spectator, and as the Irish say 'Go n-éirí an bother leat ' (may the road rise to meet you) on your journey to Ireland.

Oh, and remember to bring a rain coat, just in case, as if it's not raining it is usually because it has either just stopped or is about to start. However, for all the geophysical manufacturers out there, this provides perfect opportunities for testing the weather proof-ness of their equipment. Every anomaly has a positive and a negative!

The author would also like to thank Xstrata Zinc Ireland Ltd. and Minco plc for their permission to use the data included in this report. 